\title{
Trends in the daily and extreme temperatures in the Qiantang River basin, China
}

\author{
Fang Xia, ${ }^{a}$ Xingmei Liu, ${ }^{\text {a* }}$ Jianming Xu, ${ }^{\text {a }}$ Zhonggen Wang, ${ }^{b}$ Jingfeng Huanga \\ and Philip C. Brookes ${ }^{\mathrm{a}}$ \\ ${ }^{a}$ College of Environmental and Natural Resource Sciences, Zhejiang University, Hangzhou 310058, China \\ ${ }^{\mathrm{b}}$ Institute of Geographic Sciences and Natural Resources Research, CAS, Beijing 100101, China
}

\begin{abstract}
Temporal and spatial changes in the annual and seasonal temperatures in a typical basin of the Qiantang River were analysed based on the time series databases of daily temperatures from 14 meteorological stations. Both the Mann-Kendall (MK) trend test and simple linear regression analyses were employed to detect trends in the mean and extreme temperatures. The temperature changes during the three periods of 1960-1990, 1960-2000 and 1960-2006 were investigated at each meteorological station and over the entire basin as an average. The spatial and temporal changes were characterized by significant warming throughout the region, with the minimum temperature (Tn) increasing the most, particularly after 1990. Various percentiles of extreme temperatures, as well as their corresponding frequencies, were chosen to explore the trends of extreme climate change in this region. Linear regression analyses showed a significant warming trend in cold events both on an annual and seasonal basis, especially in the winter. Conversely, the hot events were dominated by an insignificant warming trend $(p>0.05)$. When comparing the time series before and after 1990, trend shifts were apparent in both the mean and extreme temperatures, particularly in the spring and winter. In addition to the large-scale circulation, regional factors may have influenced the observed climate change in the studied region. Climate change has already influenced human society by, for example, increasing the frequency of haze in the study region. We conclude that the warming here is mainly attributed to changes in the minimum temperature.
\end{abstract}

KEY WORDS Qiantang River basin; climate change; temperature; extreme climate events

Received 2 September 2013; Revised 21 January 2014; Accepted 22 January 2014

\section{Introduction}

In recent years, climate change, especially global warming, has received increasing attention worldwide. The Intergovernmental Panel on Climate Change(IPCC, 2007) reported that the global mean temperature has increased by nearly $0.7^{\circ} \mathrm{C}$ in the last century, with the rate of change almost doubling in the last 50 years. Previous research focused primarily on the long-term trends in mean temperatures (Liu et al., 2004). However, extreme events, such as heat waves, droughts and floods, have had increasing impacts on human society (Epstein, 2005). Furthermore, a constant or slight change in mean temperature can result in large fluctuations in temperature extremes, which are of particular concern. Consequently, it is necessary to study extreme temperature events as well as changes in mean temperature.

Average and extreme temperature changes in the 20th century have been studied worldwide. The changes in both mean and extreme temperatures in China were investigated by Qi and Wang (2012). A distinct decreasing trend in the

\footnotetext{
* Correspondence to: X. Liu, College of Environmental and Natural Resource Sciences, Zhejiang University, Hangzhou 310058, China. E-mail: xmliu@zju.edu.cn
}

extreme high and low temperatures in summer occurred in central China, but an opposite trend occurred in both the north and south before 1990. After 1990, however, the entire country has experienced a warming trend for both the mean, high and low extreme temperatures in summer, especially in the north. An investigation in South America demonstrated that there was no consistent trend in the daily maximum temperatures, but there was a significant trend in the minimum temperature (Vincent et al., 2005). In the summer of 2003, most parts of Europe, including France, Germany and Italy, suffered from an extreme heat wave, which resulted in the loss of human lives and incurred large financial costs. A conceptual framework (Stott et al., 2004) was used to estimate the anthropogenic contribution and revealed that human activities are very likely to double the risks of occurrence of such a heat wave (confidence level $>90 \%$ ). Furthermore, Europe may experience heat waves more frequently in the near future. Bonsal et al. (2001) identified a significant increase in the low percentiles of daily $\mathrm{Tn}$, as well as in the high percentiles of maximum temperature in Canada during the last century. They found seasonal variations in the number of days with extremes of low and high temperature. To better predict changes in temperature over the next century, improved climate models were applied to estimate the frequency and 
intensity of climate events under a changing climate (Tao et al., 2012). The accuracy of the predictions of extreme climatic events varied with the minimum and maximum temperature regimes in different regions, which are statistically valid over much of the planet (Hamilton et al., 2012). In contrast, some studies showed that model projections may underestimate the increase in heavy precipitation with warming and consequently underestimate the impact of heavy rainfall on human society (Min et al., 2011).

Earlier studies demonstrated that daily and extreme temperature changes vary between regions. Warming trends do not appear simultaneously worldwide and are more pronounced in the northern than in the Southern Hemisphere (Easterling et al., 1997). It is well-known that individual extreme climatic events involve specific impact areas and durations. Some extreme events are insignificant on a large scale, such as in a national context, but can be significant at the sub-regional scale. Various methods have been proposed to identify changes in regional climates, such as 'candied fruit', an objective identification technique to evaluate regional climatic extremes (Ren et al., 2012). Rotated principal component analysis was used to identify the variability of regional climate change in the United States (Lauritsen and Rogers, 2012). As stated above, it is crucial to analyse the influence of climate warming on regional climate change.

The Qiantang River basin, an important region in the Yangtze River Delta, plays a crucial role in the economic development of eastern China and provides a fresh water supply to Zhejiang province. Previous studies have examined the entire Yangtze River basin, focusing on the mean maximum and minimum temperatures (Su et al., 2006). Gong et al. (2004) conducted a survey in eastern China and found a warming trend in both the extreme high and low temperatures in summer. Xu et al. (2013) performed an investigation of the upper region of the Lanjiang basin, a sub-region of the Qiantang River basin, to evaluate the potential effect of climate change on the local hydrology in the 21 st century. Few detailed studies have been executed in the Qiantang River basin, especially with respect to climate change at multiple scales, which strongly influences the hydrological cycle (Immerzeel et al., 2010). Because little research has focused on climate change analysis in this region, especially regarding the effect of extreme events on local society, it is important to analyse historical climatic changes in order to improve water management in different regions in the future.

This study examined trends in the daily and extreme temperatures in the Qiantang River basin. Three periods of daily data, from 1960 to 1990,1960 to 2000 and 1960 to 2006 , were used to analyse the spatial and temporal changes of temperature in the region. To better understand the changes in extreme temperatures in this region, several temperature extremes with different magnitudes of intensity and frequency were compared, along with the temperature averages, to determine the changes in extreme climatic events. The average changes in temperature throughout the region were also assessed to obtain accurate information on climate change both on an annual and seasonal basis.

\section{Materials and methods}

\subsection{Study region}

The Qiantang River, a famous sightseeing area in East China, is located predominantly in Zhejiang Province and originates on the borders of the Anhui and Jiangxi provinces. The main stream length is approximately $688 \mathrm{~km}$ and flows into Hangzhou Bay, with a drainage of approximately $55600 \mathrm{~km}^{2}$. There are three sub-basins in the Qiantang River catchment: Lanjiang, Xin'anjiang, and Fuchunjiang. There is considerable geographical variation, and the climate is heterogeneous over the basin, due to the powerful impact of monsoon weather, which is characterized by hot rainy summers and cold dry winters. Dominated by a sub-tropical monsoon climate, the annual mean temperature is approximately $17^{\circ} \mathrm{C}$, with an annual average minimum of $12.9^{\circ} \mathrm{C}$, an annual average maximum of $21.3^{\circ} \mathrm{C}$ and an annual mean precipitation of approximately $1545 \mathrm{~mm}$. The basin has experienced notable climate changes during the past few decades and has suffered from floods and droughts for the past century (ZMA, 2004). Therefore, the characterization of climate change in this region is important for disaster forecast.

To obtain a comprehensive understanding of the climatic changes in the Qiantang River basin, we analysed changes during three periods, from 1960 to 1990,1960 to 2000 and 1960 to 2006. Both seasonal and annual changes were evaluated to investigate the spatial and temporal variation in the temperature indices.

\subsection{Meteorological stations}

To determine the climate change in the river basin during the past decades, we attempted to cover the greatest possible variability in climate. We therefore determined the length of the time series and estimated missing data in the stations prior to the analyses, and, finally 14 stations were selected for this study. The meteorological stations are uniformly distributed (Figure 1) in the sub-basins of the research area, with four in Xin'anjiang, four in Lanjiang and six in Fuchunjiang (Table 1).

To investigate the climate change in the Qiantang River basin, we used the time series of daily temperature, including the maximum temperature (Tm), minimum temperature (Tn) and average temperature (Tav) data, from these stations. These data were mainly obtained from the China Meteorological Data Sharing Service System and the Zhejiang Meteorological Administration. Due to poor instrumentation before 1960, meteorological records were incomplete and inaccurate. Therefore, we selected data from 1960 onwards to ensure the quality and consistency of the series.

\subsection{Methodology}

Many factors can influence the quality of meteorological data, such as urbanization, instrumentation and relocation, 


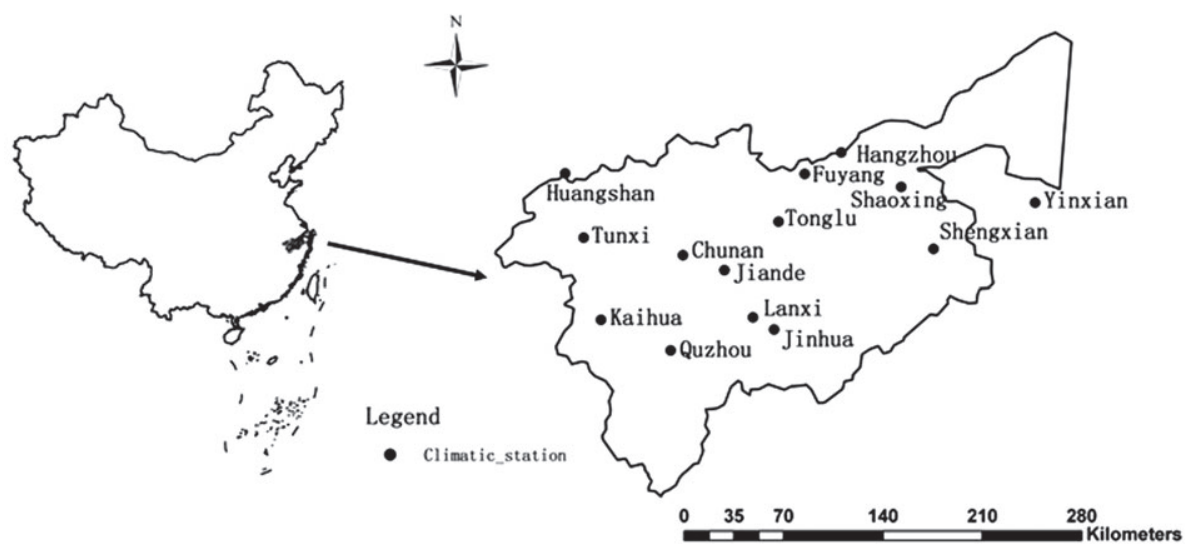

Figure 1. Location of study region and climatic stations.

Table 1. Investigated station list.

\begin{tabular}{lccrl}
\hline $\begin{array}{l}\text { Station } \\
\text { name }\end{array}$ & $\begin{array}{c}\text { Longitude } \\
\left({ }^{\circ} \mathrm{E}\right)\end{array}$ & $\begin{array}{c}\text { Latitude } \\
\left({ }^{\circ} \mathrm{N}\right)\end{array}$ & $\begin{array}{c}\text { Altitude } \\
(\mathrm{m})\end{array}$ & Sub-basin \\
\hline Tunxi & 118.28 & 29.72 & 142.7 & Xinanjiang \\
Hangzhou & 120.17 & 30.23 & 41.7 & Fuchunjiang \\
Jinhua & 119.65 & 29.12 & 62.6 & Lanjiang \\
Shengxian & 120.82 & 29.60 & 104.3 & Fuchunjiang \\
Yinxian & 121.57 & 29.87 & 4.8 & Fuchunjiang \\
Quzhou & 118.90 & 29.00 & 82.4 & Lanjiang \\
Lanxi & 119.50 & 29.20 & 45.6 & Lanjiang \\
Jiande & 119.30 & 29.50 & 30.4 & Xinanjiang \\
Shaoxing & 120.60 & 30.00 & 25.7 & Fuchunjiang \\
Fuyang & 119.90 & 30.10 & 47.2 & Fuchunjiang \\
Tonglu & 119.70 & 29.80 & 33.5 & Fuchunjiang \\
Chunan & 119.00 & 29.60 & 171.4 & Xinanjiang \\
Kaihua & 118.40 & 29.20 & 160.8 & Lanjiang \\
Huangshan & 118.15 & 30.13 & 1840.4 & Xinanjiang \\
\hline
\end{tabular}

which can result in inhomogeneous temperature records. Various methods were applied in the monthly and annual data analysis to adjust for inhomogeneity (Martín et al., 2012), but it is difficult and complicated to eliminate inhomogeneity in daily temperature records. Therefore, in this study, we mainly focused on the missing data for simplicity. The data quality control was conducted through the software Rclimdex (http://cccma.seos.uvic.ca/ETCCMI). The missing data were mostly randomly distributed in the long records, so we sought to replace the missing daily observations with the averages of neighbouring days. We found that the mean annual average value of the amended data was remarkably similar to the original data. The monthly, seasonal and annual mean temperatures were then computed from the daily series, along with the maximum and minimum temperatures. The seasons were divided into spring (March to May), summer (June to August), autumn (September to November) and winter [December to February (following year)]. The temperature indices were chosen to represent the seasonal and annual climatic characteristics and temperature extremes in the study region (Table 2). The regional average temperatures were computed by an area-weighted method, termed the Theissen polygon method (Nicholls et al., 1996). In this study, we selected the data which have apparent characteristics or relevant to climate disaster, such as extreme temperature, to describe our results, and the data that were irrelevant or showed no variations were not presented here.

\subsubsection{Serial autocorrelation}

Because the data must be independent in nonparametric trend analysis, the autocorrelation of the time series was tested. The presence of autocorrelation in a series will have a significant influence on the trend analysis, where positive autocorrelation leads to overestimation and negative autocorrelation results in underestimation. In our study, the annual Tn, Tm, Tav and the majority of the extreme cold indices showed significant autocorrelation for most climate stations. Consequently, the pre-whiting approach was employed to exclude serial autocorrelation from the original data and. Detailed information about pre-whiting method can be found in $\mathrm{Hu}$ et al. (2012).

\subsubsection{Trend analysis}

In this study, the trend in temperature at a single station, as well as regional averages, were estimated by the Mann-Kendall (MK) test and simple linear regression. The nonparametric MK test (Mann, 1945; Kendall, 1975), which can be run without assuming any particular distribution, is widely used in climate research, and thus was employed in this study to estimate the trends in the temperature indices at each station. Detailed information can be found in $\mathrm{Hu}$ et al. (2012). Simple linear regression was used to evaluate the temperature trends in the regional averages by applying anomalies rather than the raw temperature data. Linear regression was applied to all the variables and all the periods as regional averages, along with the significance, to estimate the temperature trends and the magnitude of climate changes.

\subsubsection{Change point analysis}

A climatic change point describes sudden climate change that is detectable over the time-scale of a human lifetime. 
Table 2. Investigated indices of temperature.

\begin{tabular}{|c|c|c|c|}
\hline Indices & Description & Units & Property \\
\hline Tav & Daily mean temperature & ${ }^{\circ} \mathrm{C}$ & Absolute \\
\hline $\operatorname{Tm}$ & Daily maximum temperature & ${ }^{\circ} \mathrm{C}$ & Absolute \\
\hline $\mathrm{Tn}$ & Daily minimum temperature & ${ }^{\circ} \mathrm{C}$ & Absolute \\
\hline DTR & Daily temperature range & ${ }^{\circ} \mathrm{C}$ & Absolute \\
\hline Hot days & Frequency of daily maximum temperatures $>35^{\circ} \mathrm{C}$ & days & Absolute \\
\hline Frost days & Frequency of daily minimum temperatures $<0{ }^{\circ} \mathrm{C}$ & days & Absolute \\
\hline $\operatorname{Tm}(90,95,99)$ & Percentiles of daily maximum temperature in a year & ${ }^{\circ} \mathrm{C}$ & Relative \\
\hline $\operatorname{Tn}(10,5,1)$ & Percentiles of daily minimum temperature in a year & ${ }^{\circ} \mathrm{C}$ & Relative \\
\hline $\operatorname{Tmd}(90,95,99)$ & Days of Tm $>$ long term mean $(90,95,99)$ th percentile & days & Relative \\
\hline $\operatorname{Tnd}(10,5,1)$ & Days of $\mathrm{Tn}<$ long term mean $(10,5,1)$ th percentile & days & Relative \\
\hline
\end{tabular}

According to earlier studies (Niu et al., 2004), trends in meteorological variables change significantly after a change point. To detect change points in the time series, the longest study period was examined by the cumulative anomalies method (Fernández-Montes and Rodrigo, 2012). The result was confirmed by the Kolmogorov-Smirnov (K-S) test (Young, 1977), a nonparametric method to determine whether two independent samples come from the same population.

\section{Results}

\subsection{Single station change}

The MK trend test results for the stations on an annual basis during the three study periods are summarized in Table 3, and details of some indices are provided in Table 4. From the MK results during the three periods (Table 3), the number of stations showing significant trends and the magnitude of the temperature indices differed. During 1960-1990, these temperature indices mainly indicated negative trends. However, positive trends became dominant in the longer term (1960-2000 and 1960-2006). Comparing the three periods, the temperature trends from 1960 to 2000 and 1960 to 2006 were much more similar, especially for the extreme temperature indices. As the study period became longer, more stations recorded significant trends in temperature. During 1960-2006, the trends were more apparent. Extreme hot events, including the various percentiles of Tm and their corresponding frequencies, showed increasing trends. The trends in extreme cold events, however, were more complex. The various percentiles of $\mathrm{Tn}$ at most stations were characterized by notable increasing trends, while the numbers of days with various percentiles of Tn (Tnd10, Tnd5, Tnd1) showed significant decreasing trends.

The trends in annual Tav, Tn and Tm showed the greatest differences in the three periods (Table 4). The annual Tav decreased during 1960-1990 and increased during the longer periods of 1960-2000 and 1960-2006. The trend in the annual Tm was consistent with that of the annual Tav. The annual Tn in all the three periods was dominated by positive trends, especially during 1960-2006. The magnitudes of the changes in the annual Tn were smaller for shorter time series. The diurnal temperature range (DTR) is the difference between the Tm and Tn; therefore, changes in Tn and Tm will greatly affect the DTR change. As stated above, the behaviour of annual Tn and Tm exhibited temporal differences. This resulted in the absence of temporal coherence in the number of stations with a significant trend in DTR (Table 3). However, the faster rate of increase of $\mathrm{Tn}$ than $\mathrm{Tm}$ narrowed the value of the DTR, which may have decreased in the magnitude of the trend in the DTR. The absolute indices showed no spatial distribution feature, except for the spatially consistent increase in Tav (data not shown).

To better understand the spatial distribution of the change in intensity of extreme temperatures, the trends of various percentiles of Tn and Tm during 1960-2006 are shown in Figure 2. The percentiles of extreme temperatures showed some differences between the extreme highs and lows. All of the extreme low temperatures in the stations, except Tn1 at the Quzhou station, demonstrated significant warming trends, with the largest increases among the measured extreme lows observed for Tn1. The most extreme low value of $\operatorname{Tn} 1$ was detected at the Fuyang station, with a temperature of $-9.9^{\circ} \mathrm{C}$ in 1997 , while the lows for Tn5 and Tn10 were both detected at Kaihua in 1963 , with temperatures of -6.5 and $-2.9^{\circ} \mathrm{C}$, respectively. However, few stations showed significant trends in the extreme high temperatures. In terms of spatial distribution, the inland stations experienced cooling tendencies, whereas positive tendencies prevailed in the coastal and northern regions. The largest changes in these extreme hot indices were all detected in Yinxian, with increase of $0.44,0.36$ and $0.36^{\circ} \mathrm{C} /$ decade for Tm99, Tm95 and Tm90, respectively.

Significant negative trends were detected throughout the region in the frequencies of the three extreme low temperatures (Tnd1, Tnd5 and Tnd10) (Figure 3). The peak value of Tnd1 was detected in Yinxian, with 22 days in 1963. The Jinhua and Hangzhou stations experienced the most days of Tnd5 and Tnd10, respectively. The magnitudes of the three extreme cold events changed in the order of Tnd1 $(-1.2$ days/decade $)<$ Tnd5 $\quad(-3.2$ days/decade $)<$ Tnd 10 $(-4.1$ days/decade). The extreme high temperatures varied with the extreme lows. Among all the stations, Jiande and Kaihua experienced the most days with extreme high temperatures, especially in 1971. The insignificant trends in Tmd1, Tmd5 and Tmd10, which showed both increases 
Table 3. Number of stations with trend: -, significant negative trend; +, significant positive trend; 0 , no trend or insignificant trend.

\begin{tabular}{|c|c|c|c|c|c|c|c|c|c|}
\hline \multirow[t]{2}{*}{ Indices } & \multicolumn{3}{|c|}{$1960-1990$} & \multicolumn{3}{|c|}{$1960-2000$} & \multicolumn{3}{|c|}{ 1960-2006 } \\
\hline & - & 0 & + & - & 0 & + & - & 0 & + \\
\hline $\operatorname{Tn}$ & 1 & 12 & 1 & 0 & 9 & 5 & 0 & 3 & 11 \\
\hline $\mathrm{Tm}$ & 5 & 9 & 0 & 0 & 13 & 1 & 0 & 8 & 6 \\
\hline Tav & 7 & 7 & 0 & 0 & 13 & 1 & 0 & 9 & 5 \\
\hline DTR & 6 & 8 & 0 & 7 & 7 & 0 & 3 & 11 & 0 \\
\hline Frost days & 4 & 10 & 0 & 13 & 1 & 0 & 14 & 0 & 0 \\
\hline Hot days & 1 & 12 & 0 & 2 & 10 & 1 & 0 & 12 & 1 \\
\hline Tnd1 & 9 & 5 & 0 & 13 & 1 & 0 & 13 & 1 & 0 \\
\hline Tnd5 & 8 & 6 & 0 & 13 & 1 & 0 & 14 & 0 & 0 \\
\hline Tnd10 & 2 & 12 & 0 & 14 & 0 & 0 & 14 & 0 & 0 \\
\hline Tmd90 & 5 & 9 & 0 & 3 & 10 & 1 & 0 & 13 & 1 \\
\hline Tmd95 & 3 & 11 & 0 & 3 & 10 & 1 & 0 & 12 & 2 \\
\hline Tmd99 & 0 & 14 & 0 & 0 & 13 & 1 & 0 & 12 & 2 \\
\hline Tn1 & 0 & 2 & 12 & 0 & 2 & 12 & 0 & 1 & 13 \\
\hline Tn5 & 0 & 7 & 7 & 0 & 1 & 13 & 0 & 0 & 14 \\
\hline Tn10 & 0 & 11 & 3 & 0 & 2 & 12 & 0 & 0 & 14 \\
\hline Tm90 & 0 & 12 & 2 & 4 & 9 & 1 & 0 & 13 & 1 \\
\hline Tm95 & 3 & 11 & 0 & 2 & 11 & 1 & 0 & 10 & 4 \\
\hline Tm99 & 0 & 14 & 0 & 2 & 11 & 1 & 0 & 12 & 2 \\
\hline
\end{tabular}

Trends significant at the 0.05 level (MK test).

Table 4. Slopes of MK test in three study periods for absolute variables of the stations.

\begin{tabular}{|c|c|c|c|c|c|c|c|c|c|}
\hline \multirow[t]{2}{*}{ Stations } & \multicolumn{3}{|c|}{$1960-1990$} & \multicolumn{3}{|c|}{$1960-2000$} & \multicolumn{3}{|c|}{ 1960-2006 } \\
\hline & Tav & $\mathrm{Tm}$ & Tn & Tav & $\mathrm{Tm}$ & Tn & Tav & $\mathrm{Tm}$ & $\mathrm{Tn}$ \\
\hline Tunxi & -0.07 & -0.33 & 0.12 & 0.05 & 0.00 & 0.12 & 0.02 & 0.03 & 0.12 \\
\hline Hangzhou & 0.00 & -0.14 & 0.18 & 0.14 & 0.10 & 0.15 & 0.16 & 0.15 & 0.18 \\
\hline Jinhua & -0.21 & -0.14 & 0.00 & 0.04 & 0.00 & 0.17 & 0.09 & 0.10 & 0.13 \\
\hline Shengxian & -0.17 & -0.18 & -0.11 & 0.09 & 0.12 & 0.00 & 0.11 & 0.15 & 0.11 \\
\hline Yinxian & 0.04 & 0.00 & 0.17 & 0.15 & 0.14 & 0.23 & 0.16 & 0.19 & 0.20 \\
\hline Quzhou & -0.15 & -0.25 & -0.07 & 0.00 & 0.05 & 0.00 & 0.09 & 0.11 & 0.03 \\
\hline Lanxi & -0.22 & -0.26 & 0.01 & 0.00 & -0.01 & 0.12 & 0.08 & 0.10 & 0.13 \\
\hline Jiande & -0.21 & -0.25 & 0.01 & -0.10 & -0.07 & 0.10 & 0.02 & 0.02 & 0.11 \\
\hline Shaoxing & -0.13 & -0.25 & -0.15 & 0.01 & 0.03 & -0.01 & 0.09 & 0.11 & 0.12 \\
\hline Fuyang & -0.17 & -0.18 & -0.06 & 0.04 & 0.06 & 0.10 & 0.19 & 0.15 & 0.16 \\
\hline Tonglu & -0.25 & -0.39 & -0.05 & -0.04 & -0.08 & -0.40 & 0.06 & 0.08 & 0.13 \\
\hline Chunan & -0.22 & -0.33 & -0.07 & 0.00 & -0.08 & 0.06 & 0.08 & 0.04 & 0.11 \\
\hline Kaihua & -0.11 & -0.21 & 0.13 & 0.01 & -0.10 & 0.21 & 0.09 & -0.03 & 0.24 \\
\hline Huangshan & 0.00 & 0.00 & 0.00 & 0.10 & 0.09 & 0.11 & 0.12 & 0.12 & 0.13 \\
\hline
\end{tabular}

Numbers with bold italics indicate significance at the 0.05 level (MK test).

and decreases, were in contrast to the frequencies of the extreme low temperatures, which exhibited a simple decreasing trend. The spatial characteristics of the frequencies of extreme hot events were dominated by increasing trends in the coastal stations, in contrast to the negative trends or absence of trends in the inland stations. This result differs slightly from those of other studies, such as research in the Yellow River source region that showed a simple increase in the frequency of extreme hot days (Hu et al., 2012).

\subsection{Regional average change}

\subsubsection{Annual change}

To characterize the changes in temperatures throughout the region, the changes in the regional annual average are given as temperature anomalies in the three periods in Figure 4. Compared to the baseline period (1960-1990), the periods of 1960-2000 and 1960-2006 showed slight differences in these temperature trends. Tn, Tm and Tav, together with DTR, showed significant trends during 1960-2006, whereas few changes occurred from 1960 to 2000. The annual Tav, Tn and Tm have increased by $0.17,0.21$ and $0.15^{\circ} \mathrm{C} /$ decade during 1960-2006, respectively, representing larger changes than those reported earlier for the Northern Hemisphere (IPCC, 2007). The warming magnitudes of these indices in 1960-2006 were greater than those in 1960-2000, except for the DTR, which showed a greater decline in the latter period because of the two anomalous years of 2005 and 2006 for the DTR. As stated before, the change in the DTR was attributed to the changes in both Tn and Tm. The different changes in the DTR during the two periods (1960-2000 and 1960-2006) were due to the significant 

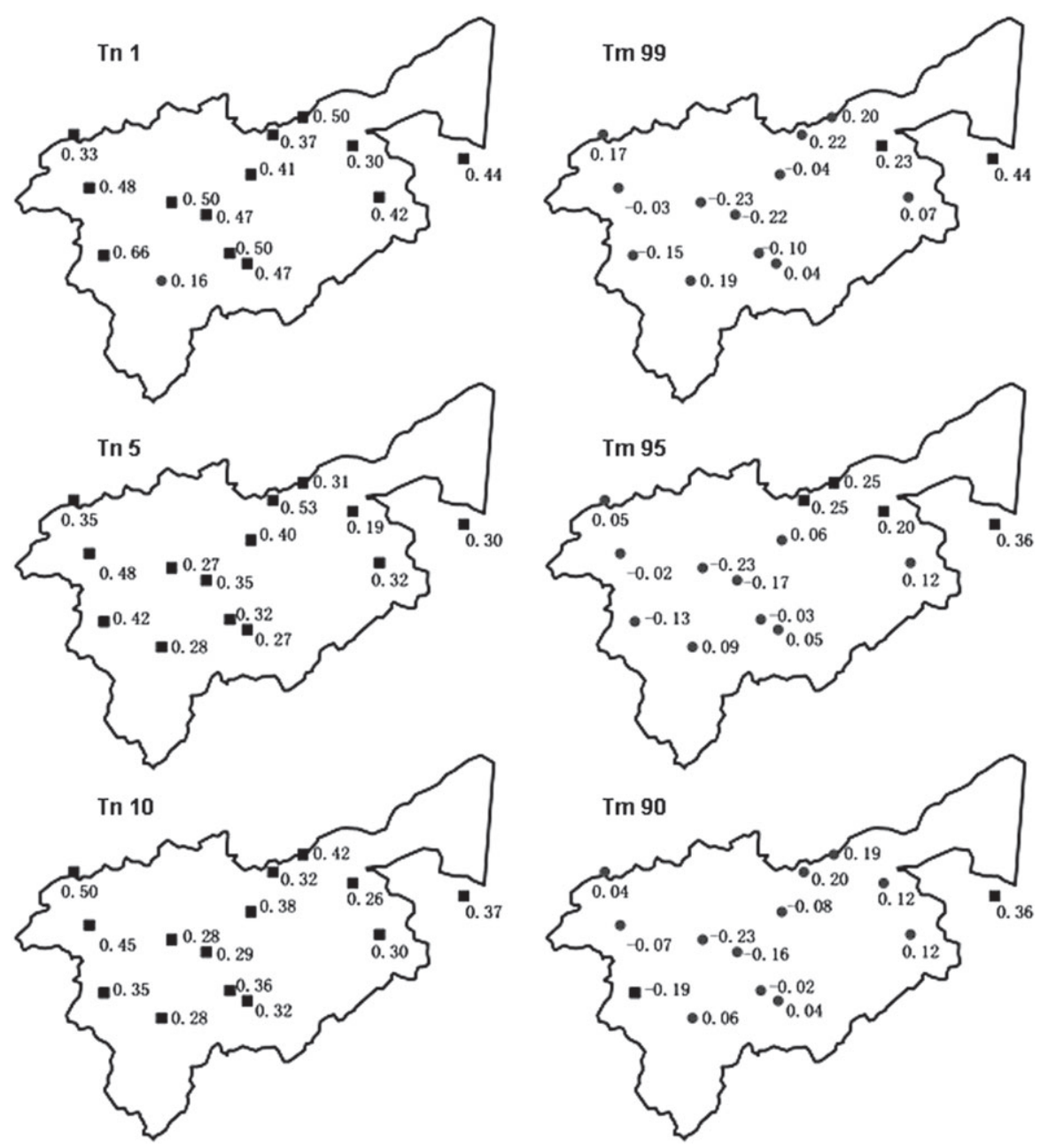

Figure 2. Trends for extreme temperature percentiles in the study region for the period of $1960-2006\left({ }^{\circ} \mathrm{C} / \mathrm{dec}\right.$ ade $)$. Significant trends are marked with squares $(0.1$ level) and insignificant trend or no trends are marked with grey dots.

increase in Tn and Tm after 1990. Consequently, the values after 1990 made a big difference on the trend analysis for these absolute temperature indices.

In contrast to the absolute temperatures cited above, the changes in extreme temperature percentiles were more apparent during 1960-2006 (Figure 5). The three extreme low temperature percentiles for the regional average showed similar consistent warming trends, and, after 1990, there was a greater increase in these trends than observed prior to 1990 . The large increase after 1990 contributed to the significant warming trend during 1960-2006, as stated above. The annual Tn10 of the regional average showed the greatest increase of $0.17^{\circ} \mathrm{C}$ /decade after 1990. Conversely, the three extreme high temperature percentiles exhibited more complex trends. Before 1980, the three extreme high temperature percentiles of the regional average fluctuated in a downward trend, but, after 1990, they began to fluctuate upward. This resulted in an insignificant trend in the regional averages for the extreme high temperatures.

The regional annual average frequencies of the extreme temperature percentiles during 1960-2006 are shown in Figure 6, which demonstrated a significant decrease in the number of days with extreme low temperature percentiles. The magnitude of the trend in Tnd10 was -4.12 days/decade, which was the greatest change of the three percentiles. In contrast, the trends in Tmd90, Tmd95 and Tmd99 for the regional average were characterized by a decreasing trend prior to the 1980 s and an insignificant increase after the 1980s. The magnitudes of the three frequencies related to extreme hot events were much smaller than those of the extreme cold events. However, the linear regression was insignificant for these three frequencies during 1960-2006. The trends in the frequencies of extreme cold events and hot events were different but showed the same patterns of change within their own groups. The trends in the frequencies of hot days and frost days were similar to the trends in the extreme temperatures. As stated above, the changes in the numbers of days with extreme high and low temperatures indicate a warming climate in the study region.

\subsubsection{Seasonal change}

We mainly focused on change point analysis in the seasonal analysis in this study. The cumulative anomaly results show that significant climate change points varied 

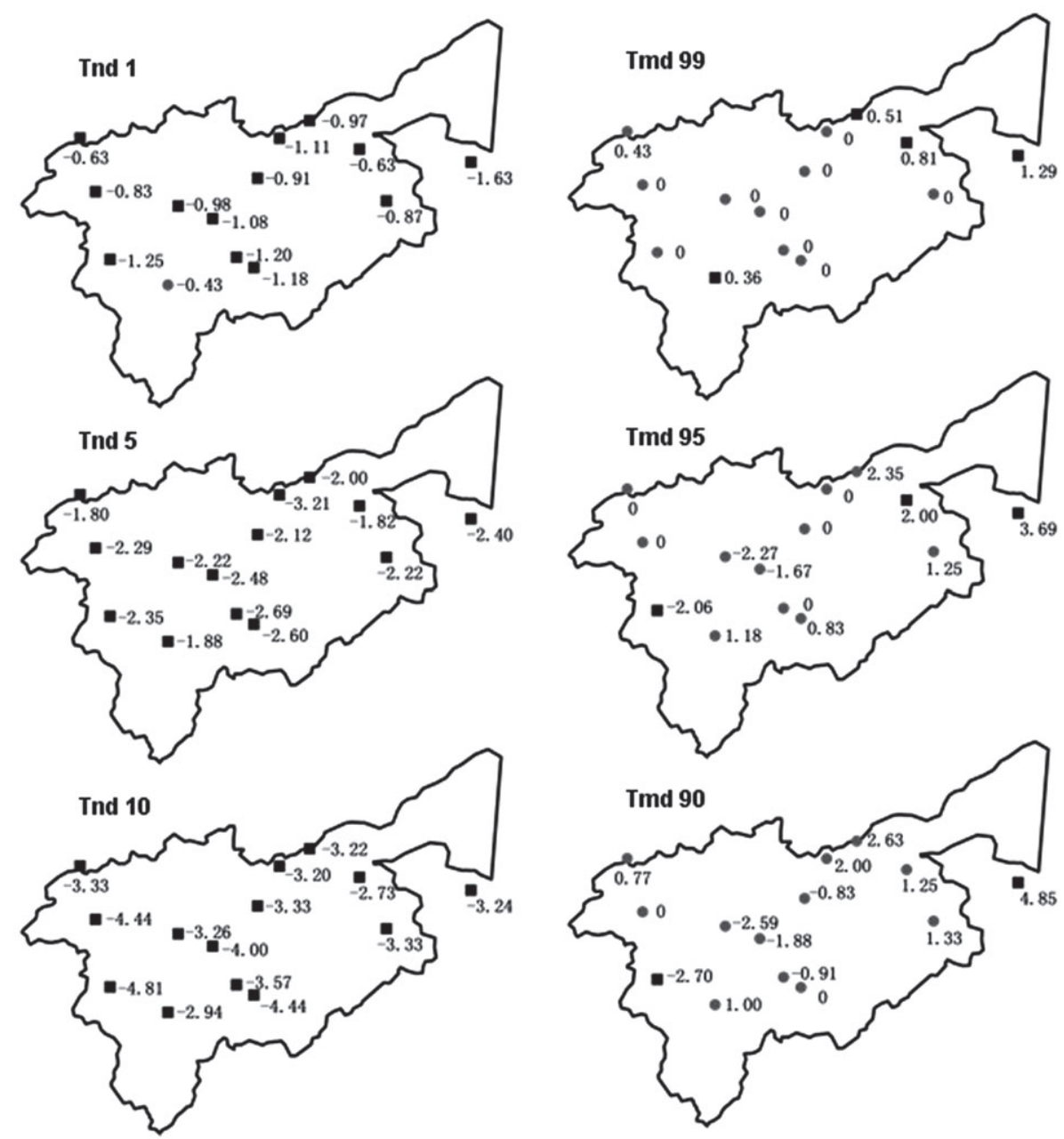

Figure 3. Trends for frequencies of extreme temperature percentiles in the study region for the period of 1960-2006 (days/decade). Significant trends are marked with squares $(0.1$ level) and insignificant trend or no trends are marked with grey dots.

with different indices and with the seasons. Most of the temperature indices showed a significant shift around the late 1980s and early 1990s, and 1990 was therefore designated a climate change point. The result of the $\mathrm{K}-\mathrm{S}$ test showed that the majority of the indices, including the absolute and relative ones, had significant differences between the two sub-periods, which supported the selection of the change point. The majority of the extreme low temperature percentiles and their corresponding frequencies underwent a significant shift after 1990. However, the extreme cold events did not display the same behaviour. The indices with a change point varied with the seasons, and the results from the spring and winter measurements are shown in Figure 7. Before 1990, the extreme low temperature percentiles in the spring declined, while they increased markedly and with a larger magnitude in the winter. The extreme high temperature percentiles showed an upward tendency in the spring and a downward tendency in the winter, with the magnitude of the change larger in the spring. After 1990, both the trends and their corresponding magnitudes changed. The magnitudes of the trends became larger in the spring without changing direction, with the exception of Tm99. The trends were more complicated in the winter, with both increases and decreases in the extreme events. The most interesting finding is that there was a cessation of the warming of the extreme low temperature percentiles in the winters after 1990, which was also observed in north China for cold temperatures (Qi and Wang, 2012).

The changes in the frequencies of the extreme temperature percentiles in the summer and winter are of interest (Figure 8). The changes in the extreme hot events were similar to those of the cold events, which decreased before 1990 and increased after 1990. The magnitudes of the trends in the cold events were much larger for the winters prior to 1990 , and after 1990, the hot events in summer increased. Furthermore, the magnitudes were consistent between the various percentiles in the group, where trend magnitude of the days with the most extreme temperature percentiles (Tn1 and Tm99) were the smallest in the two sub-periods and seasons. However, the changes in the two sub-periods were statistically significant $(p<0.05)$ only in the winter. The trends of hot days in the summer and frost days (statistics not shown) in the winter were characterized by similar characteristics in the two sub-periods for the days of extreme high and low temperature percentiles in the two seasons. 

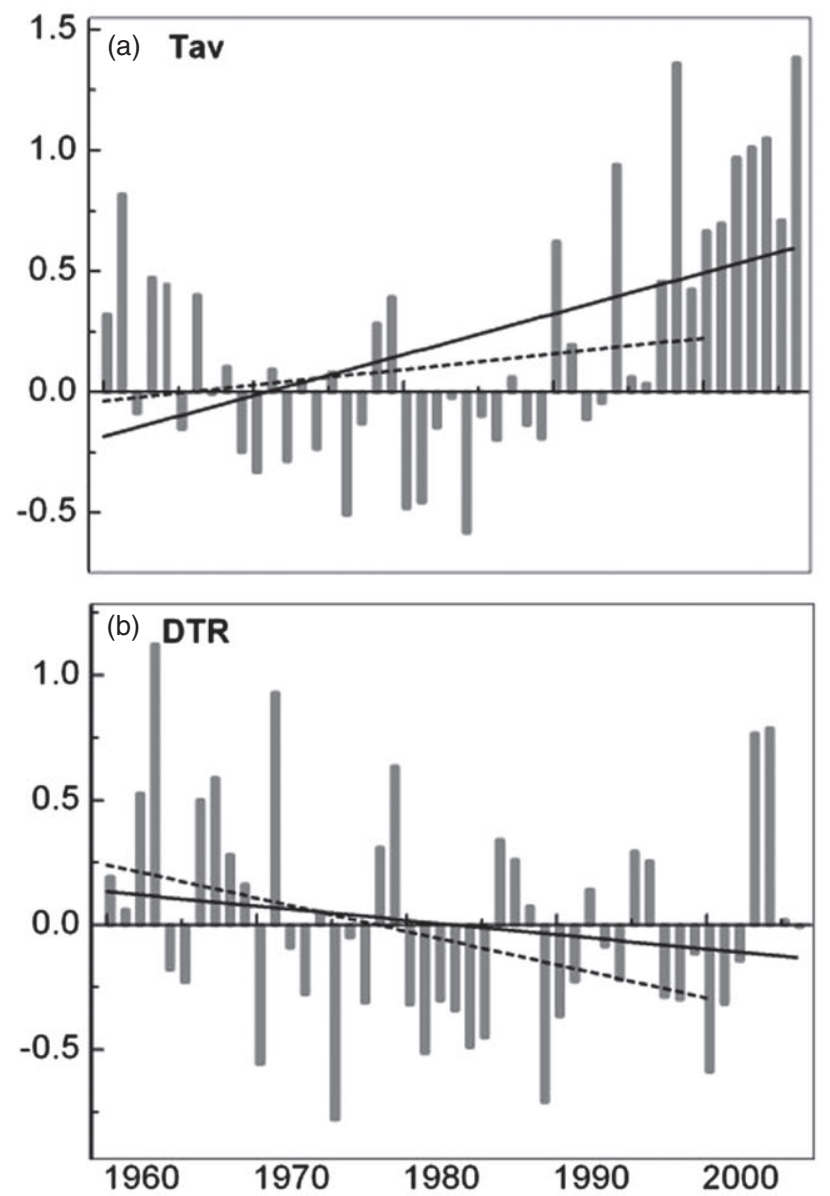
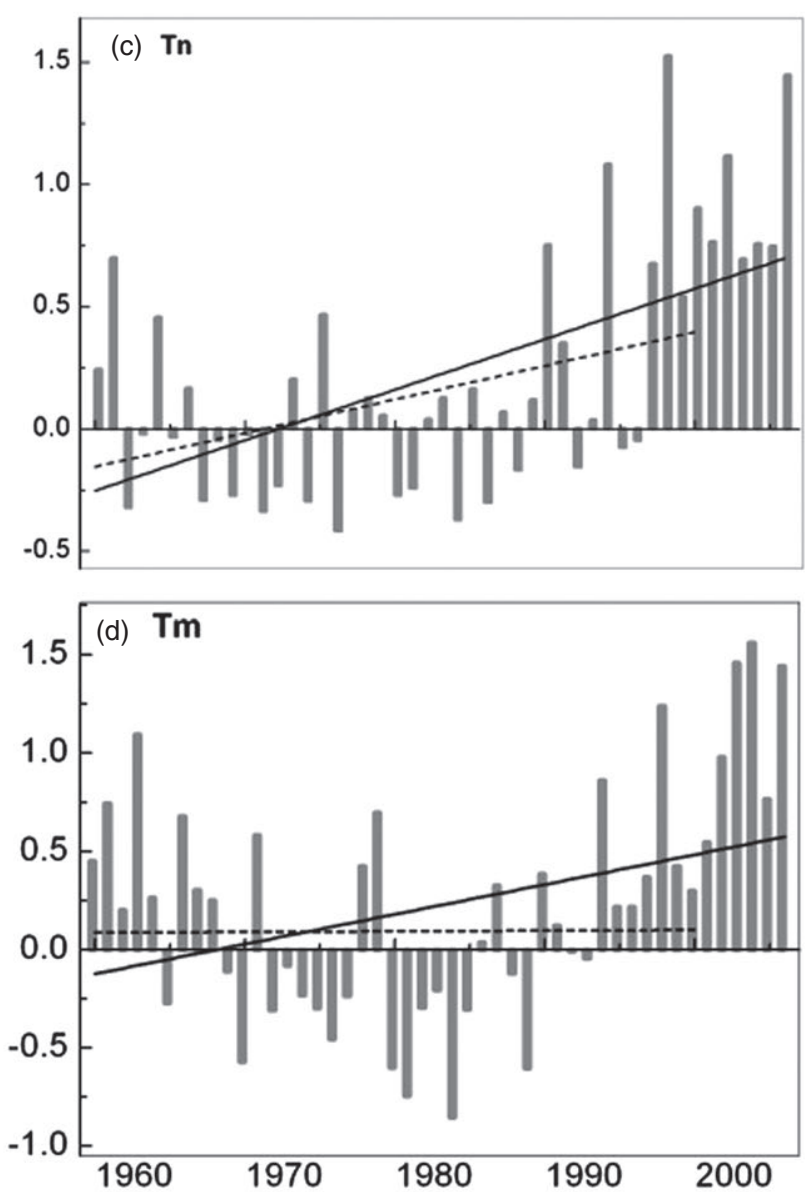

Figure 4. Trend of annual region anomalies in temperatures. The straight lines represent the linear regressions for the periods $1960-2006$ and dotted lines for 1960-2000, respectively. Baseline period for anomalies refers to 1960-1990.

\section{Discussion}

The climate in the study region is clearly warming as suggested previously in other studies of China (Qi and Wang, 2012). Significant warming trends were detected throughout the region and for all seasons in the study region, especially for the extreme cold events. Combined with the greenhouse effect, some regional factors in the study region were related to the observed regional climate change. The Xin' anjiang reservoir manages the water resources in the study region and was built in approximately 1960. Because of the presence of the Xin'anjiang reservoir in the study region, the climatic stations showed some spatial differences. Chun'an and Jiande, which are close to the reservoir, experienced a minor change in the $\mathrm{Tm}$ index $\left(0.03,-0.01^{\circ} \mathrm{C} /\right.$ decade, respectively) compared to the stations located farther away. It was reported previously that the reservoir plays a potential role in regional climate change, especially in the Tm (Chen et al., 2009). The complexity of the changes in the Tn and Tm over the last two decades is related to the significance of the changes in the DTR. The trend in the DTR in the study region, however, is in agreement with an earlier study of global DTR changes (Vose et al., 2005). In contrast to the Tn and Tm for the two longer periods, the trend was larger in magnitude for the period from 1960 to 1990. This is in agreement with investigations of the DTR throughout China (Liu et al., 2004). Previous studies revealed that cloud cover changes are related to changes in the DTR, and the cloud cover in China was shown to decrease, which should result in an increased DTR (Qian et al., 2006). However, in this study, the DTR decreased, in contrast to the expectation based on cloud cover changes. This is consistent with the results from investigations covering all of China (Liu et al., 2004) but in contrast to some other parts of the world (Dai et al., 1997).

The extreme temperatures, including the low and high percentiles of Tn and Tm, exhibited spatial and temporal characteristics. These indices demonstrated that the warming trend in extreme events was significant, especially over the last two decades, which experienced the most intense warming of entire period (1960-2006). Furthermore, the extreme low temperature percentiles in autumn and winter showed a significant increase, while the extreme high temperature percentiles showed no changes in trend or magnitude. The same conclusion was reached for the changes in the extreme low temperatures, which are correlated with the large increase in greenhouse gases in recent decades. The region investigated in this study is dominated by monsoons, especially in the summer. Previous studies revealed that central Pacific EI Niño events increased after 1990 

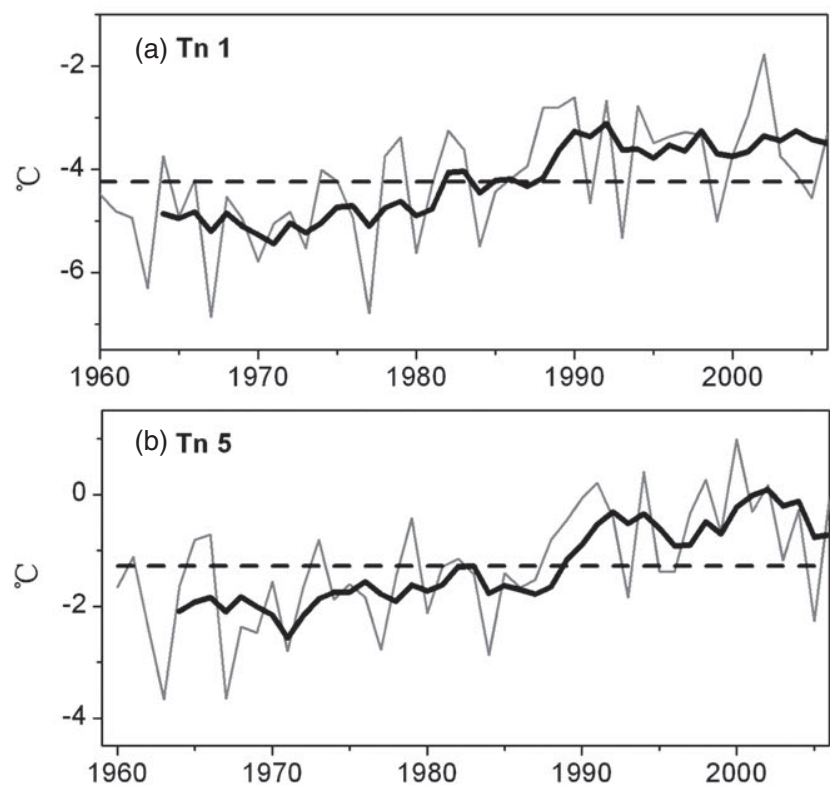

(c) Tn 10

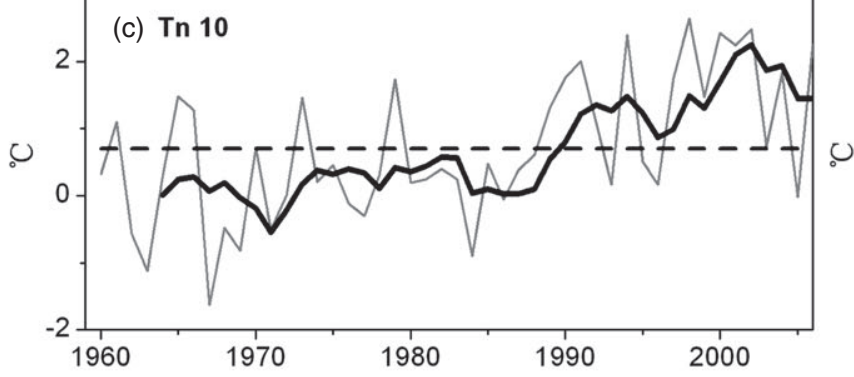

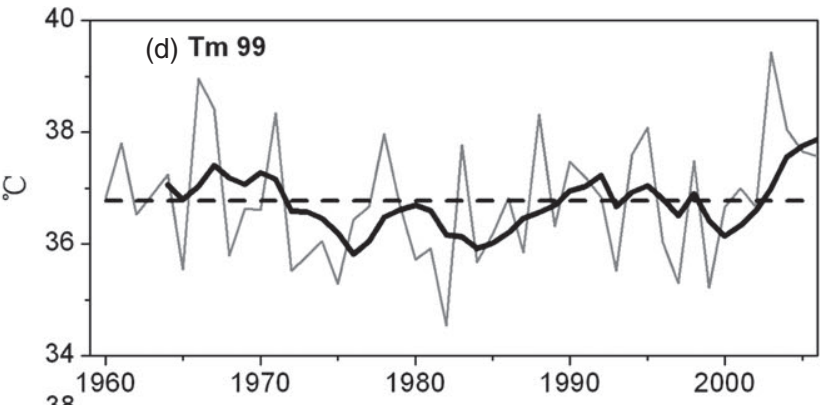

(e) $\operatorname{Tm} 95$
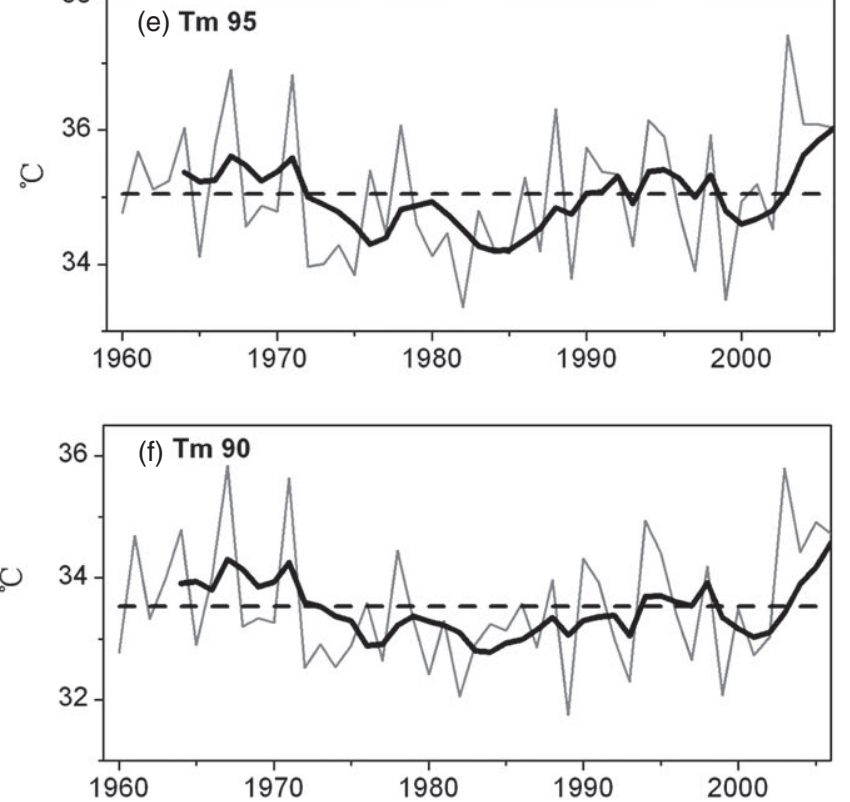

Figure 5. Time series for annual region averaged extreme temperatures $\left({ }^{\circ} \mathrm{C}\right)$. Thin grey curves show the regional average. Horizontal red lines show the indices averages during 1960-2006. Thick black curves show 5 years moving averages.

(Zhang et al., 2011). It is inferred that this weakened the East Asia summer monsoon, thereby altering the precipitation distribution, which finally resulted in slowing the warming in southern China in the summer (Qi and Wang, 2012). Qi and Wang (2012) also found that the large circulation of the Arctic Oscillation was likely to induce a decrease in the cold temperatures in northern China in the winter after 1990, which was also identified in this study in terms of the of extreme low temperature percentiles in winter after 1990. Furthermore, irrigation has also been found to be related to regional climate change through water-vapour feedback. A regional model was applied in California to estimate the irrigation cooling effect on the regional climate. The Tm during May to October was found to be the most significantly influenced due to the increased soil moisture caused by irrigation (Kueppers et al., 2007). Irrigation is widely practiced in the study region, with flood-irrigation supplemented by furrow-irrigation. Combined with dispersed farming, which is much different from that in Europe and America, where intensive agriculture prevails, the duration of irrigation lasts longer and will therefore influence the regional climate substantially. Reclamation projects, a type of land management, are widely practiced in the study region to meet the demands of urban construction.
It was reported that these changes in land-use could affect the regional climate (Yan et al., 2002). The water areas in the study region, including coastal beaches and shallows, have been reclaimed for arable and residential land over recent decades. In the last two decades, the water area has decreased by $12.7 \%$ (Yao et al., 2007). This reclamation will certainly modify the land surface flux of heat energy and water vapour, which would alter the energy available for extreme temperatures and change their spatio-temporal patterns (Pielke, 2005)

The entire region displayed a significant trend toward fewer days with extreme low temperatures, with some differences between the seasons. This result is consistent with the projection by the IPCC that the number of frost days and cold events will decrease. It was reported that summer is dominated by western Pacific subtropical highs, especially in south-eastern China, which is related to the number of days with extreme high temperatures in summer (Zhang et al., 2008). In this study, however, the trend in the frequency of extreme hot events showed an insignificant increase in the summer, together with less spatial coherence. Furthermore, the magnitude was largest in spring rather than in summer. This conflicts with the modelling results of the IPCC, which predicted more days with extreme high temperatures in the summer. This trend 

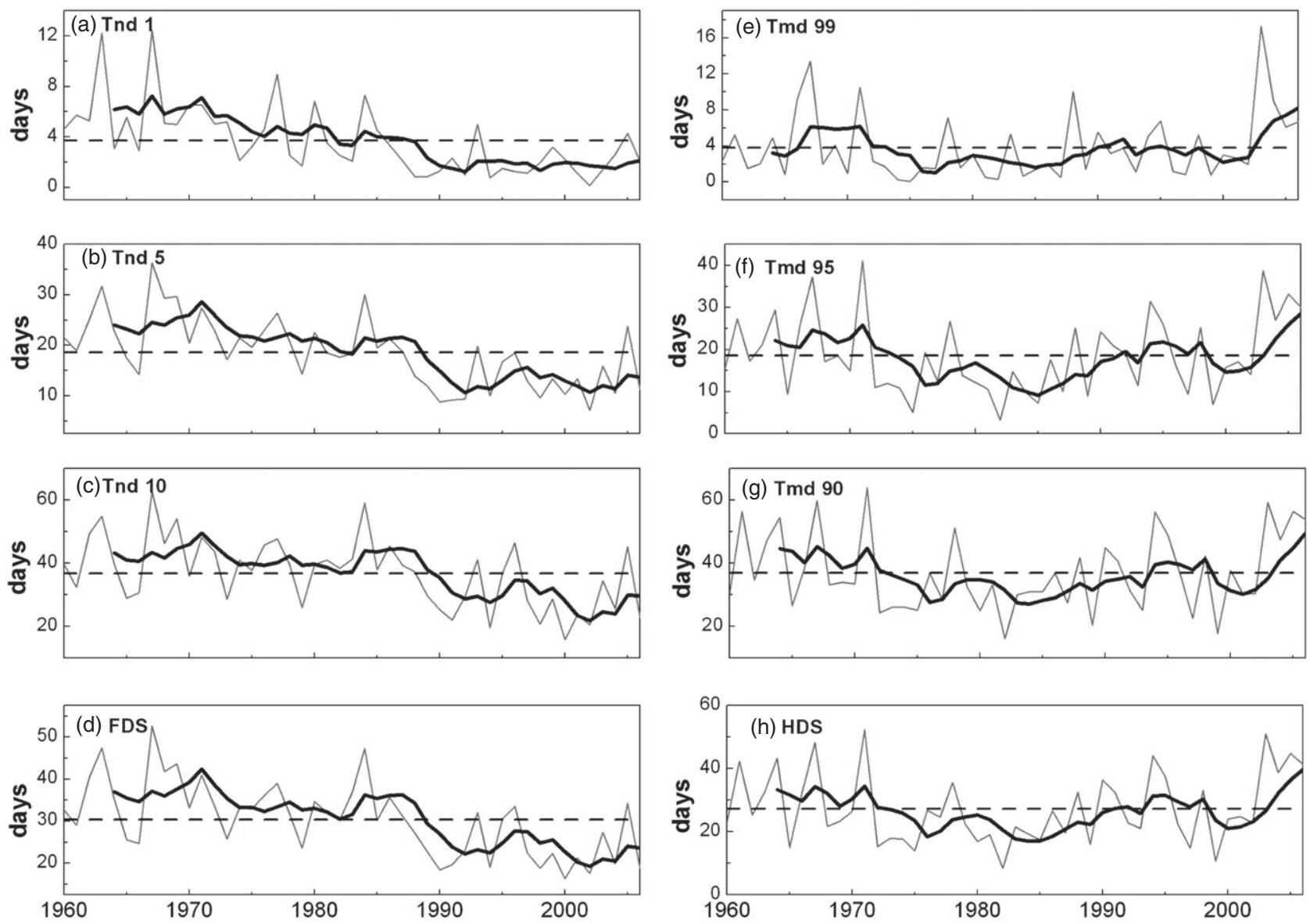

Figure 6. Time series for absolute temperature indices for the annual region averaged over days/decades. Thin curves show the regional average. Horizontal dotted lines show the average from 1960 to 2006. Thick curves show 5 years moving averages.

changed after 1990, before which decreases were observed in all seasons except the spring. The mechanisms causing these changes in the frequency of extreme temperatures have been discussed widely and are believed to be significantly correlated with large-scale atmospheric circulations. Studies of the North Atlantic Oscillation considered the effect of enhanced greenhouse gases (Nogaj et al., 2006). The correlation with the North Atlantic Oscillation was found to be insignificant in their work, conflicting with recent research in China (Qi and Wang, 2012). Recently, the Potsdam Institute for Climate Impact Research proposed an atmospheric wave quasiresonance equation to explain the mechanism of several recent extremes and suggested that some quasiresonant wave amplification, which is related to climate extremes, may occur rather frequently (Petoukhov et al., 2013).

The study region is one of the most economically developed areas in China, making it susceptible to increasing environmental pollution, for example, fine suspended particles including aerosols. Aerosols, including PM2.5, which can carry heavy metals and organic pollutants and would lead to haze, are becoming a serious public health concern (Pope et al., 2002). These aerosols, which have increased in the late 20th century (Streets et al., 2008), influence solar radiation and cloud cover and significantly decrease summer maximum temperatures
(Kaiser and Qian, 2002). This phenomenon was confirmed in this study, which observed a decrease in the summer maximum temperatures. The wind speed, which was reported to have significantly decreased recently in the study region, keeps aerosols, including PM2.5, suspended in the atmosphere, resulting in a remarkable increase in haze in recent years and leading to numerous environmental and health problems (Hu and Zhou, 2009).

\section{Conclusions}

This study identified a clear pattern of climate warming, including in the mean and extreme temperatures, in the Qiantang River basin. Generally, the absolute temperature indices, including Tav, Tn and Tm, exhibited a warming pattern, and the different warming magnitudes in Tn and Tm resulted in the narrowing of the DTR. During the period of 1960-1990, the weather stations showed negative trends for the temperature indices, while after 1990 the temperature indices were dominated by positive trends. Climate change will surely redistribute extreme events in the study region. All of the selected extreme low temperature percentiles indicated warming trends, with negative trends in the corresponding frequencies. The decreases in the numbers of days with extreme low temperatures were characterized by percentiles, trending in 
Spring
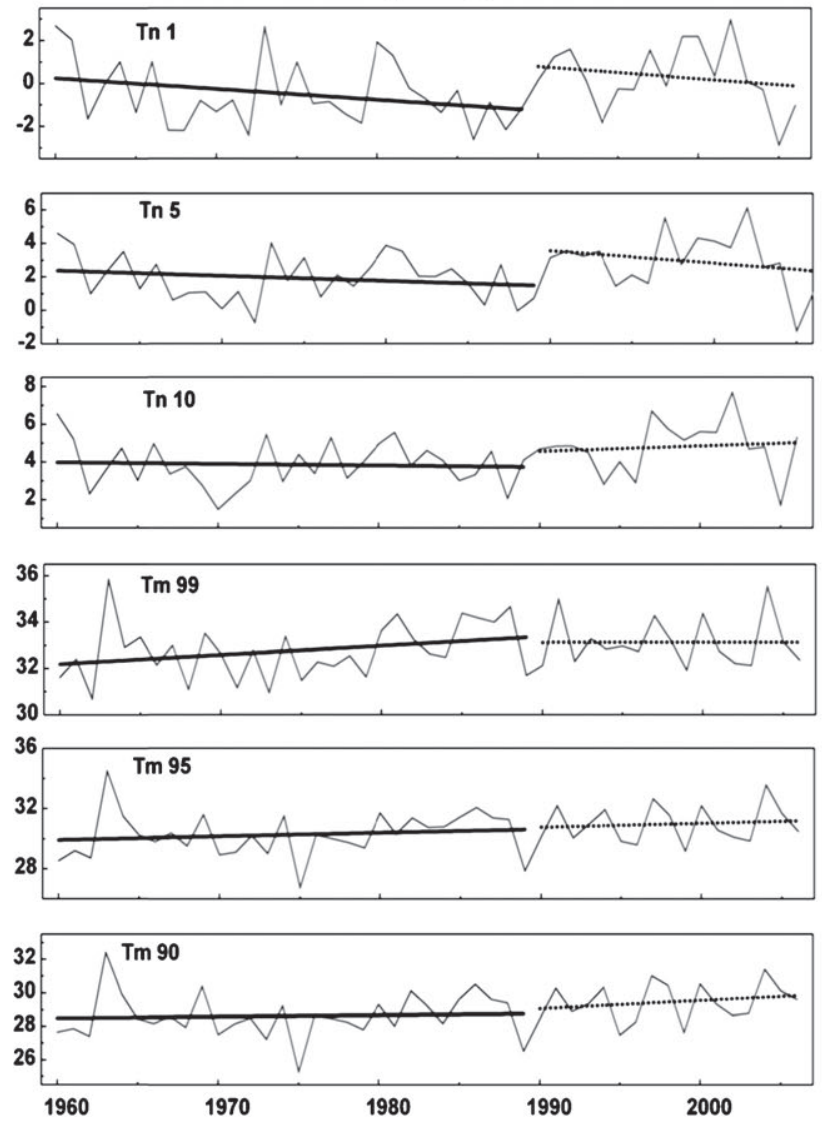

Winter
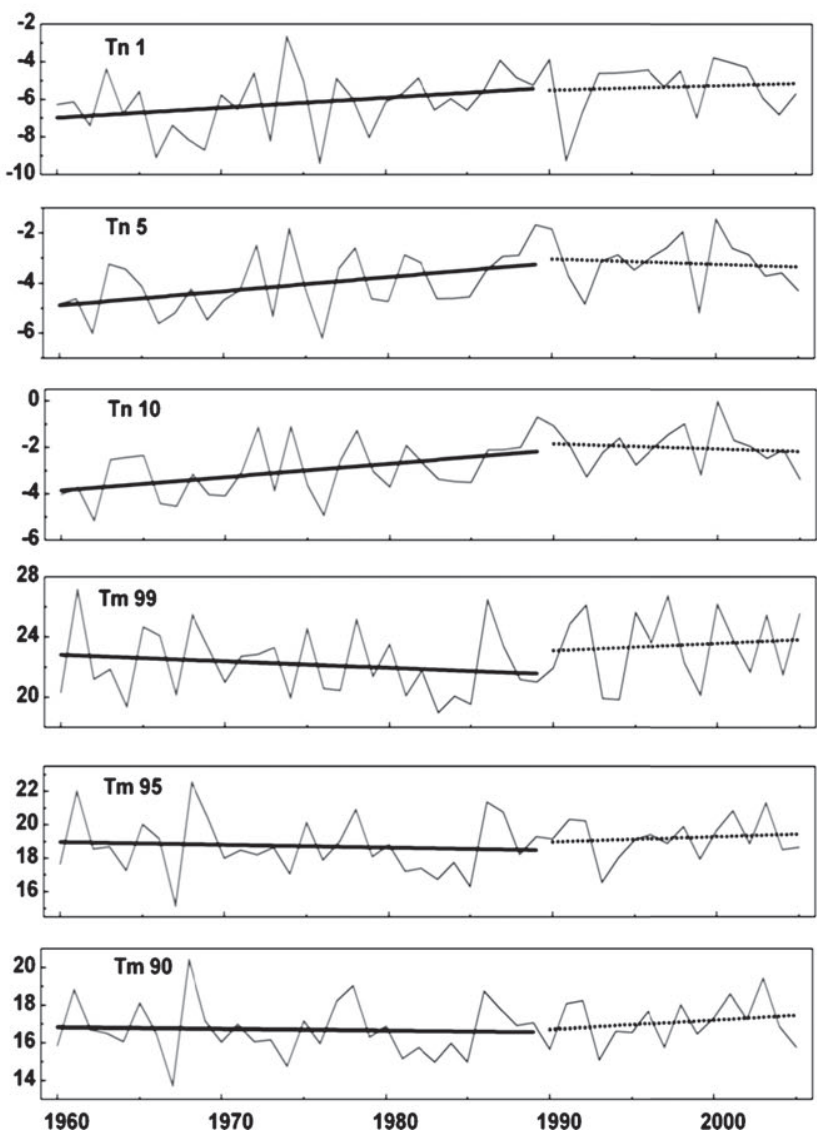

Figure 7. Time series of temperature indices in spring and winter. The grey curves show the regional average temperature $\left({ }^{\circ} \mathrm{C}\right)$. The solid and dotted lines are the linear trend before and after $1990\left({ }^{\circ} \mathrm{C} /\right.$ decade $)$.

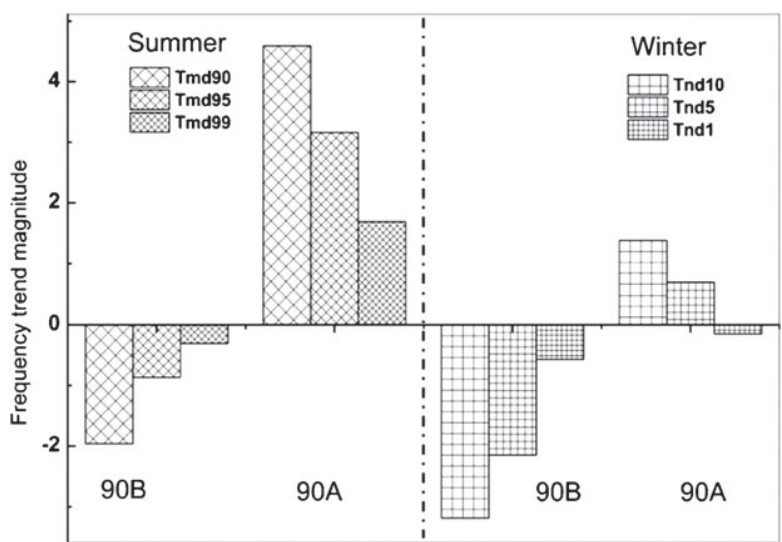

Figure 8. Summer (winter) magnitude of days with various percentiles of maximum (minimum) temperatures before and after 1990 (90B, 90A) (days/decade).

the order of Tnd $1<$ Tnd $5<$ Tnd 10 . Although the trends in the extreme high temperature percentiles and the corresponding frequencies were insignificant, they exhibited spatial features, which are summarized as follows. The extreme high temperature percentiles increased in the east and decreased in the western and central parts of the study region. The frequencies of extreme hot events increased at the coastal stations but decreased or displayed no change at the inland stations. Change points were apparent in the indices, but varied with the seasons. The $\mathrm{K}-\mathrm{S}$ results indicated more difference in the indices between 1960-1989 and 1990-2006 during the spring and winter. However, the behaviour varied with the seasons and indices. In our analysis, the extreme low temperature ceased to decrease in winters after 1990, which requires further investigation. The frequencies of extreme temperature in the winter and summer exhibited changes, with both decreasing before 1990 and increasing after 1990.

Climate warming will certainly change the probability distribution of atmospheric temperatures, which may lead to more frequent extreme events. In contrast to the cold events, the changes in the hot events were insignificant, indicating that the study region is becoming 'less cold', rather than becoming hotter. The climate changes identified in this study, which could be caused by anthropogenic greenhouse gases combined with other mechanisms, such as irrigation, cloud cover and atmospheric aerosols, showed agreement with global and regional modelling results. However, the contribution of urban 'heat islands' to the warming in the Qiantang River basin, which is mainly derived from building construction and artificial heat emissions, requires further evaluation. Because it is impossible to distinguish the influence of various factors on climate change (e.g. heat islands and 
irrigation cooling effects, which have opposite impacts on temperature), new technology is required to distinguish various climate influence in order to identify their separate contributions to climate change. More detailed investigations are needed to explain the mechanism of the regional climate change in the Qiantang River basin.

\section{Acknowledgements}

This work was sponsored by the National Natural Science Foundation project of China (41171258 and 41271048) and the Zhejiang Provincial Natural Science Foundation of China (LR13D010001). The author would like to thank the laboratory group for their assistance in data analysis.

\section{References}

Bonsal BR, Zhang X, Vincent LA, Hogg WD. 2001. Characteristics of daily and extreme temperatures over Canada. J. Climate 14: 1959-1976.

Chen XY, Zhang Q, Ye DX, Liao YM, Zhu CH, Zou XK. 2009. Regional climate change over three Gorges reservoir area (in Chinese). Resour. Environ. Yangtze Basin 1: 47-51.

Dai A, Del Genio AD, Fung IY. 1997. Clouds, precipitation and temperature range. Nature 386: 665-666.

Easterling DR, Horton B, Jones PD, Peterson TC, Karl TR, Parker DE, Salinger MJ, Razuvayev V, Plummer N, Jamason P. 1997. Maximum and minimum temperature trends for the globe. Science 277: 364-367.

Epstein PR. 2005. Climate change and human health. New Engl. J. Med. 353: $1433-1436$

Fernández-Montes S, Rodrigo FS. 2012. Trends in seasonal indices of daily temperature extremes in the Iberian Peninsula, 1929-2005. Int. J. Climatol. 32: 2320-2332.

Gong DY, Pan YZ, Wang JA. 2004. Changes in extreme daily mean temperatures in summer in eastern China during 1955-2000. Theor. Appl. Climatol. 77: 25-37.

Hamilton E, Eade R, Graham RJ, Scaife AA, Smith DM, Maidens A, MacLachlan C. 2012. Forecasting the number of extreme daily events on seasonal timescales. J. Geophys. Res. 117: 3114.

$\mathrm{Hu}$ YD, Zhou ZJ. 2009. Climatic characteristics of haze in China (in Chinese). Meteorol. Mon. 35: 73-78.

Hu YR, Maskey S, Uhlenbrook S. 2012. Trends in temperature and rainfall extremes in the Yellow River source region, China. Clim. Change 110: 403-429.

Immerzeel WW, van Beek LP, Bierkens MF. 2010. Climate change will affect the Asian water towers. Science 328: 1382-1385.

Intergovernmental Panel on Climate Change (IPCC). 2007. Climate Change 2007: The Fourth Assessment Report of the IPCC. Cambridge University Press: Cambridge, UK.

Kaiser DP, Qian Y. 2002. Decreasing trends in sunshine duration over China for 1954-1998: indication of increased haze pollution? Geophys. Res. Lett. 29: 2042.

Kendall MG. 1975. Rank Correlation Measures. Charles Griffin: London; 202.

Kueppers LM, Snyder MA, Sloan LC. 2007. Irrigation cooling effect: regional climate forcing by land-use change. Geophys. Res. Lett. 34 : L03703.

Lauritsen RG, Rogers JC. 2012. US diurnal temperature range variability and regional causal mechanisms, 1901-2002. J. Climate 25: $7216-7231$

Liu BH, Xu M, Henderson M, Qi Y, Li YQ. 2004. Taking China's temperature: daily range, warming trends, and regional variations, 1955-2000. J. Climate 17: 4453-4462.
Mann HB. 1945. Non-parametric tests against trend. Econometrica 13 245-259.

Martín JL, Bethencourt J, Cuevas-Agulló E. 2012. Assessment of global warming on the island of Tenerife, Canary Islands (Spain). Trends in minimum, maximum and mean temperatures since 1944. Clim. Change 114: 343-355.

Min SK, Zhang XB, Zwiers FW, Hegerl GC. 2011. Human contribution to more-intense precipitation extremes. Nature 470: 378-381.

Nicholls N, Lavery B, Frederiksen C, Drosdowsky W, Torok S. 1996. Recent apparent changes in relationships between the El Niño-Southern Oscillation and Australian rainfall and temperature. Geophys. Res. Lett. 23: 3357-3360.

Niu T, Chen L, Zhou Z. 2004. The characteristics of climate change ove the Tibetan Plateau in the last 40 years and the detection of climatic jumps. Adv. Atmos. Sci. 21: 193-203.

Nogaj M, Yiou P, Parey S, Malek F, Naveau P. 2006. Amplitude and frequency of temperature extremes over the North Atlantic region. Geophys. Res. Lett. 33: L10801.

Petoukhov V, Rahmstorf S, Petri S, Schellnhuber HJ. 2013. Quasiresonant amplification of planetary waves and recent Northern Hemisphere weather extremes. Proc. Natl. Acad. Sci. U. S. A. 110: 5336-5341.

Pielke RA. 2005. Land use and climate change. Science 310 $1625-1626$.

Pope CA III, Burnett RT, Thun MJ, Calle EE, Krewski D, Ito K, Thurston GD. 2002. Lung cancer, cardiopulmonary mortality, and long-term exposure to fine particulate air pollution. JAMA 287: 1132-1141.

Qi L, Wang YQ. 2012. Changes in the observed trends in extreme temperatures over China around 1990. J. Climate 25: 5208-5222.

Qian Y, Kaiser DP, Leung LR, Xu M. 2006. More frequent cloud-free sky and less surface solar radiation in China from 1955 to 2000 Geophys. Res. Lett. 33: L01812.

Ren FM, Cui DL, Gong ZQ, Wang YJ, Zou XK, Li YP, Wang SG, Wang XL. 2012. An objective identification technique for regional extreme events. J. Climate 25: 7015-7027.

Stott PA, Stone DA, Allen MR. 2004. Human contribution to the European heatwave of 2003. Nature 432: 610-614.

Streets DG, Yu C, Wu Y, Chin M, Zhao ZC, Hayasaka T, Shi GY. 2008. Aerosol trends over China, 1980-2000. Atmos. Res. 88: 174-182.

Su BD, Jiang T, Jin WB. 2006. Recent trends in observed temperature and precipitation extremes in the Yangtze River basin, China. Theor. Appl. Climatol. 83: 139-151.

Tao H, Gemmer M, Jiang J, Lai X, Zhang Z. 2012. Assessment of CMIP3 climate models and projected changes of precipitation and temperature in the Yangtze River Basin, China. Clim. Change 111: 737-751.

Vincent LA, Peterson TC, Barros VR, Marino MB, Rusticucci M, Carrasco G, Ramirez E, Alves LM, Ambrizzi T, Berlato MA. 2005. Observed trends in indices of daily temperature extremes in South America 1960-2000. J. Climate 18: 5011-5023.

Vose RS, Easterling DR, Gleason B. 2005. Maximum and minimum temperature trends for the globe: an update through 2004. Geophys. Res. Lett. 32: L23822.

Xu YP, Zhang XJ, Ran QH, Tian Y. 2013. Impact of climate change on hydrology of upper reaches of Qiantang River Basin, East China. $J$. Hydrol. 483: 51-60.

Yan MH, Deng W, Chen PQ. 2002. Climate change in the Sanjiang Plain disturbed by large-scale reclamation. J. Geogr. Sci. 12: 405-412.

Yao W, Lou JY, Zhang LS, Zhang Y, Liu P, Wu JP. 2007. Land use/Land cover dynamic in Qiantang river watershed: 1985-2004 (in Chinese). B. Sci. Technol. 4: 502-507.

Young IT. 1977. Proof without prejudice: use of the KolmogorovSmirnov test for the analysis of histograms from flow systems and other sources. J. Histochem. Cytochem. 25: 935-941.

Zhang F, Gao H, Cui X. 2008. Frequency of extreme high temperature days in China, 1961-2003. Weather 63: 46-49.

Zhang WJ, Jin FF, Li JP, Ren HL. 2011. Contrasting impacts of two-type El Niño over the Western North Pacific during Boreal autumn. $J$ Meteorol. Soc. Jpn. 89: 563-569.

Zhejiang Meteorological Administration (ZMA). 2004. Yearbook of meteorological disaster in China. Report Zhejiang Meteorological Administration. 